\title{
Aggressive fibromatosis-associated with papillary thyroid cancer: two cases and a brief review
}

\author{
Yao Li", Shichao Li", Xiaowei Qi, Wenying Fu, Fan Zhang, Xinhua Yang \\ Breast Disease Center, Southwest Hospital, Third Military Medical University, Chongqing, 400038, China \\ \#These authors contributed equally to this work. \\ Correspondence to: Fan Zhang; Xinhua Yang. Breast Disease Center, Southwest Hospital, Third Military Medical University, Chongqing 400038, \\ China. Email: zhangfan316@163.com; swhtmmu@medmail.com.cn.
}

\begin{abstract}
Aggressive fibromatosis (AF) is usually considered a benign tumor. Reports of the association between $\mathrm{AF}$ and malignancies have appeared infrequently. Herein, we report two cases of AF arising in the neck that were associated with papillary thyroid cancer. Two cases are presented in this article. One is a 31-year-old male patient who was diagnosed with AF 9 months after his thyroid cancer operation; there has been no recurrence after surgical resection and postoperative radiotherapy. The other is a 53 -year-old female patient who was diagnosed with thyroid cancer and AF simultaneously. There is still no recurrence after surgical resection, endocrine therapy and thyroid-stimulating hormone (TSH) suppression treatment. Both cases showed $\beta$-catenin positivity upon further immunohistochemistry (IHC) examination. AF is a rare and benign tumor. It can occur in association with malignancies, such as thyroid cancer. Whether a patient diagnosed with $\mathrm{AF}$ associated with thyroid cancer has a family history of a familial adenomatous polyposis $(F A P)$ mutation or $\beta$-catenin mutation should be given more attention. The treatment strategy in this situation includes surgical excision combination with radiotherapy and endocrine therapy to reduce the recurrence rate.
\end{abstract}

Keywords: Aggressive fibromatosis (AF); thyroid cancer; familial adenomatous polyposis (FAP) gene mutation; $\beta$-catenin mutation; CTNNB1 gene

Submitted Oct 28, 2018. Accepted for publication Aug 28, 2019.

doi: $10.21037 /$ tcr.2019.09.21

View this article at: http://dx.doi.org/10.21037/tcr.2019.09.21

\section{Introduction}

Aggressive fibromatosis (AF), also known collectively as desmoid tumors, is a mesenchymal tumor that arises from fascial or deep musculoaponeurotic structures. Although AF lesions do not metastasize, they can be locally invasive and exhibit a propensity to recur despite aggressive surgical resection. This rare tumor has an annual incidence of 2.10 to 5.36 cases per million (1). Approximately $38.6 \%$ of desmoid tumors arise in the abdominal region while the most common extra-abdominal sites are reported to be the trunk, extremities, head/neck and other locations (2). AF may occur sporadically or in association with familial adenomatous polyposis $(F A P)$ gene mutations as a component of Gardner's syndrome. Reports on the association of AF with malignancies have appeared infrequently. Herein, we report two cases of AF arising in the neck associated with papillary thyroid cancer.

\section{Case presentation}

Case 1

A 31-year-old male patient had been diagnosed with a left papillary micro-thyroid carcinoma (Figure 1) with node metastases and received a total thyroidectomy with bilateral central neck dissection and left lateral neck dissection in January 2014 in our hospital. After the operation, he received radioiodine treatment and thyroid-stimulating hormone (TSH) suppression treatment with levothyroxine. 


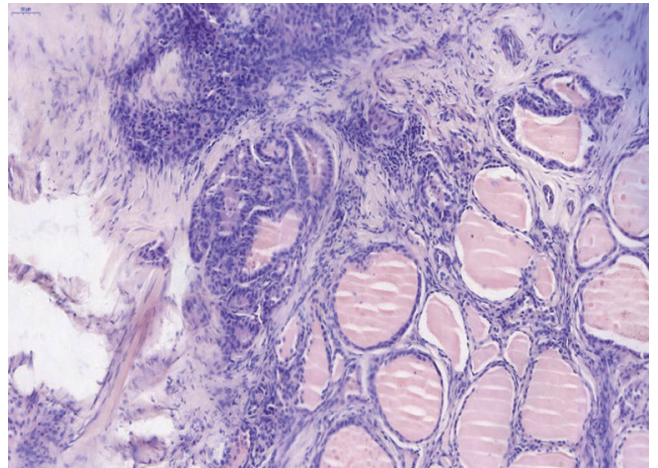

Figure 1 The pathologic image of Case 1-PTC. Hematoxylineosin staining, 20x. PTC, papillary thyroid carcinoma.

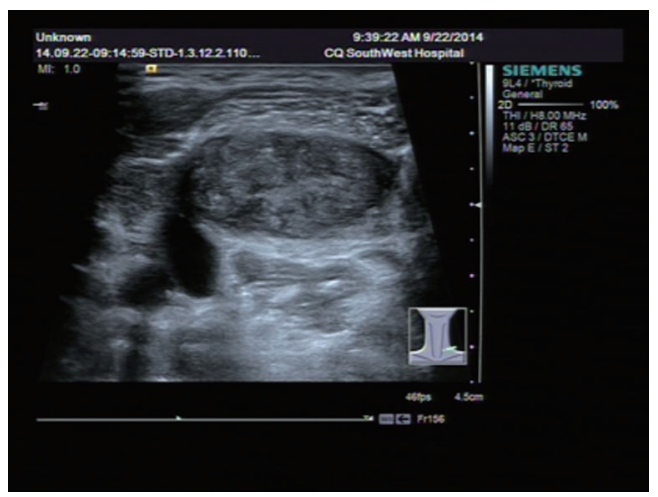

Figure 2 US image of Case 1-AF in September 2014. A heterogeneous hypoechoic lump located in the left neck, between level III and V lymph node compartment, measuring $58 \mathrm{~mm} \times$ $20 \mathrm{~mm} \times 30 \mathrm{~mm}$. US, ultrasound; AF, aggressive fibromatosis.

In September 2014, an ultrasound (US) review showed a heterogeneous hypoechoic lump located in his left neck, between the level III and V lymph node compartments, measuring $58 \mathrm{~mm} \times 20 \mathrm{~mm} \times 30 \mathrm{~mm}$ (Figure 2). Pathologic results of fine-needle aspiration cytology (FNAC) from the lump suggested a spindle cell tumor diagnosis with $\mathrm{AF}$ tendencies. When the lump increased gradually to the size of $62 \mathrm{~mm} \times 41 \mathrm{~mm} \times 46 \mathrm{~mm}$ (Figure 3), the patient came to our hospital again in July 2015 and received a secondary operation. Extensive resection was performed on his left neck under general anesthesia in August 2015. AF in his left neck was confirmed by postoperative pathologic examination (Figure 4). Further immunohistochemistry (IHC) examination showed that the mass was smooth

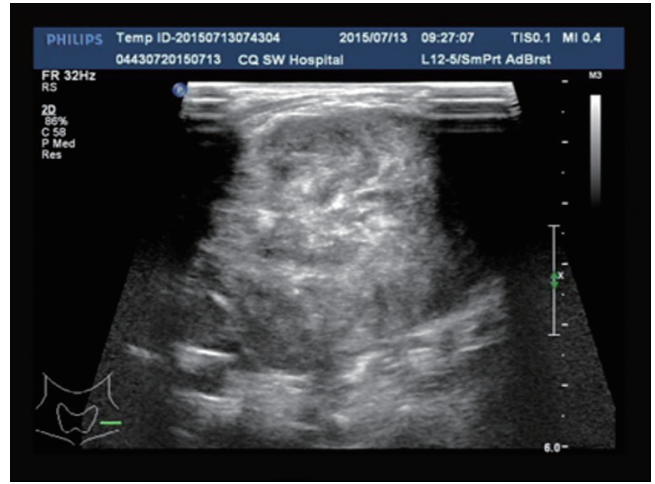

Figure 3 US image of Case 1-AF in July 2015. The lump located in the left neck had increased, measuring $62 \mathrm{~mm} \times 41 \mathrm{~mm} \times$ $46 \mathrm{~mm}$. US, ultrasound; AF, aggressive fibromatosis.

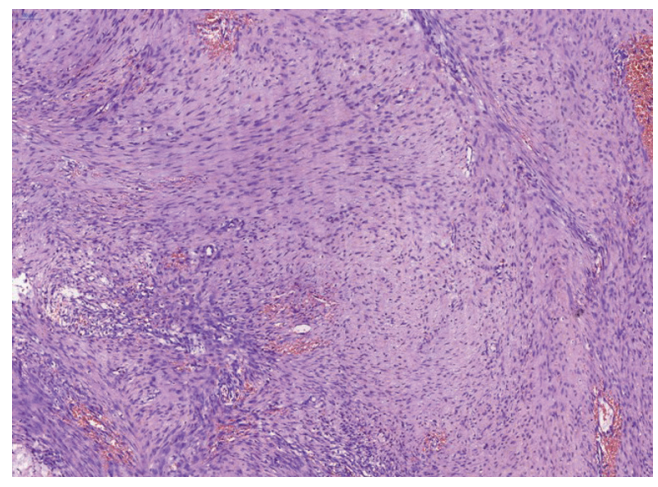

Figure 4 The pathologic image of Case 1-AF. Hematoxylin-eosin staining, 10x. AF, aggressive fibromatosis.

muscle actin (SMA) negative, $\beta$-catenin positive, CD34 positive and Desmin negative. After discharge, he received adjuvant radiotherapy, and no recurrence has occurred to date.

\section{Case 2}

A 53-year-old female patient who presented with a palpable lump in the posterior triangle of her left neck, came to our hospital in October 2014. High-resolution-US showed a heterogeneous hypoechoic lump located in her left level $\mathrm{V}$ lymph node compartment, measuring $50 \mathrm{~mm} \times 17 \mathrm{~mm}$ (Figure 5). Preoperative sonography detected another hypoechoic nodule with irregular margins in her left thyroid region. The size was approximately $7 \mathrm{~mm} \times 9 \mathrm{~mm}$ (Figure 6). 


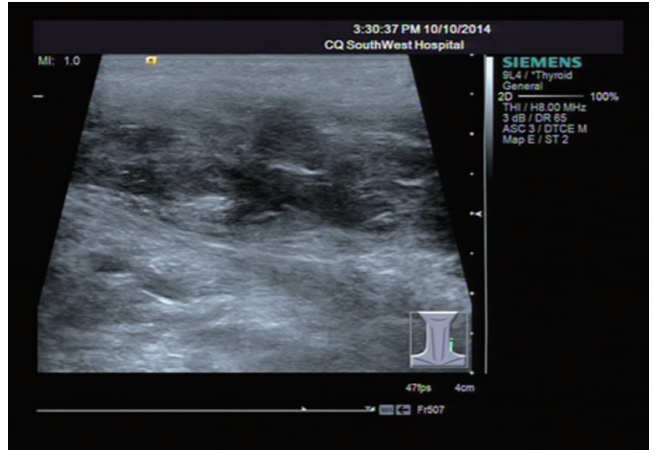

Figure 5 US image of Case 2-a lump. A heterogeneous hypoechoic lump was located in the left level $\mathrm{V}$ lymph node compartment, measuring $50 \mathrm{~mm} \times 17 \mathrm{~mm}$. US, ultrasound.

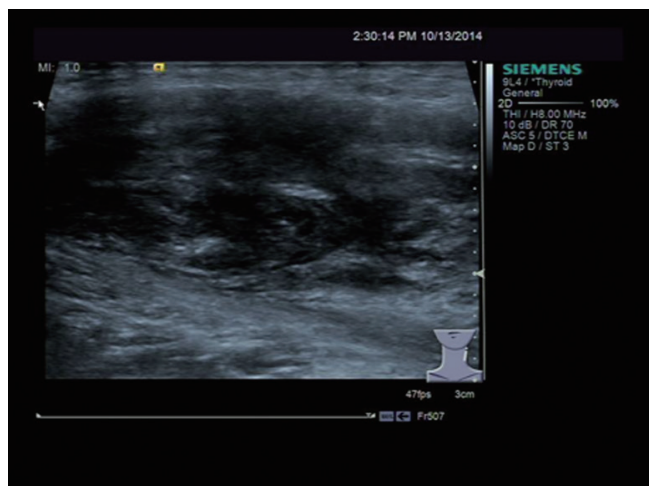

Figure 6 US image of Case 2-a nodule. Another hypoechoic nodule with irregular margins in the patient's left thyroid region, measuring $7 \mathrm{~mm} \times 9 \mathrm{~mm}$. US, ultrasound.

Physical examination and US did not find any suspicious enlarged lymph nodes in her neck. FNAC biopsy suggested that a papillary thyroid carcinoma (PTC) and spindle cell tumor were separately rendered on her left thyroid nodule and the lump in her left level V compartment. The oral administration of tamoxifen (10 mg, twice a day) for one week before surgery had no effect on the lump; then, the patient received a total thyroidectomy with bilateral central neck dissection and left lateral neck dissection. The final pathologic findings confirmed AF concomitant with left PTC without any neck lymph node metastasis (Figures 7,8). Further IHC results showed that the mass was SMA positive, caldesmon positive, CD34 positive, $\beta$-catenin nuclear staining positive and desmin negative. The patient received TSH suppression treatment with levothyroxine after discharge from our hospital and no recurrence has been observed to date.

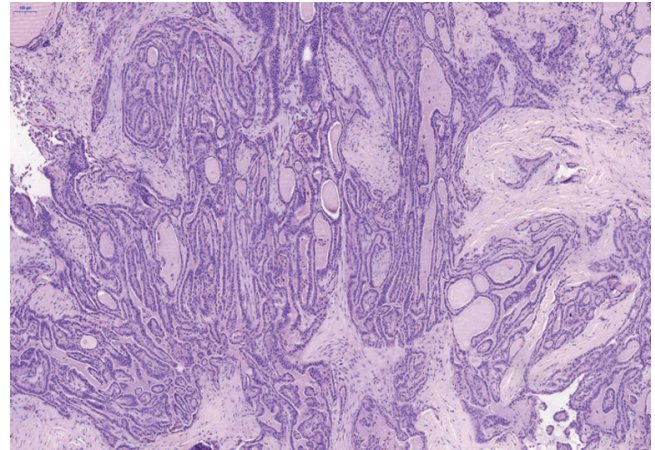

Figure 7 The pathologic image of Case 2-PTC. Hematoxylineosin staining, 10×. PTC, papillary thyroid carcinoma.

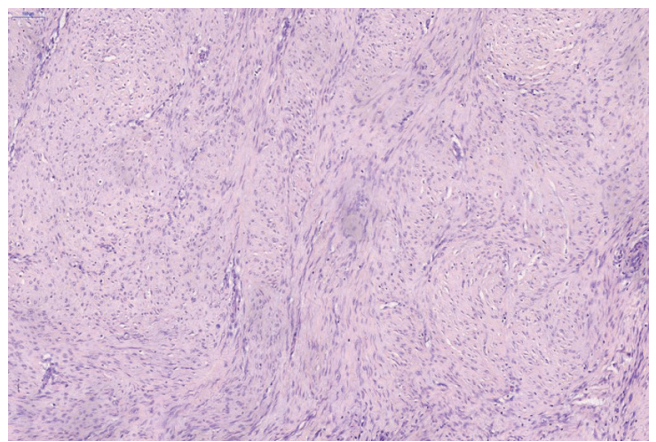

Figure 8 The pathologic image of Case 2-AF. Hematoxylin-eosin staining, 10×. AF, aggressive fibromatosis.

\section{Discussion and conclusions}

AF tumors are pathologically benign tumors that never metastasize, and they are notorious for their locally aggressive growth and recurrence; lesions may invade surrounding muscles, blood vessels and nerves (3). Although the etiology of AF is not fully understood, several factors, such as hormone status, e.g., estrogen, genetic predisposition, e.g., the FAP gene, and prior local invasion, e.g., surgery or trauma, have been implicated (4). The treatment strategy for AF includes surgical excision and in combination radiotherapy, chemotherapy and endocrine therapy to reduce the recurrence (5). Case 1 is a young patient with more extensive margins and a higher risk of recurrence, so he has accepted postoperative radiotherapy, and no recurrence has occurred so far. While there is still controversy over the effect of chemotherapy on $\mathrm{AF}$ and no recommended protocol, the two cases in this report did not accept chemotherapy. For Case 2, there was no effect after the continuous use of tamoxifen treatment for one week, 
Table 1 A review of AF associated with malignancies in the English literature.

\begin{tabular}{|c|c|c|c|c|c|c|c|c|}
\hline Case & Report & PMID & Year & AF location & $\begin{array}{l}\text { Associated with } \\
\text { malignant tumors }\end{array}$ & Surgical pattern & $\begin{array}{l}\text { Pre/post } \\
\text { operation }\end{array}$ & $\begin{array}{c}\text { Recurrence } \\
\text { (interval/month) }\end{array}$ \\
\hline 1 & Dale et al. & 8579271 & 1995 & Chest wall & Breast cancer & $\begin{array}{l}\text { Alloplastic breast } \\
\text { reconstruction }\end{array}$ & After & No report \\
\hline 2 & $\begin{array}{l}\text { Hyodo } \\
\text { et al. }\end{array}$ & 11172213 & 2001 & $\begin{array}{l}\text { Neck and } \\
\text { inguinal } \\
\text { region }\end{array}$ & $\begin{array}{l}\text { Gastric scirrhous } \\
\text { carcinoma }\end{array}$ & No surgery & Simultaneously & Death \\
\hline 3 & $\begin{array}{l}\text { Khanfir } \\
\text { et al. }\end{array}$ & 12775750 & 2003 & Chest wall & Breast cancer & $\begin{array}{l}\text { Radical mastectomy and } \\
\text { immediate reconstruction }\end{array}$ & After & No report \\
\hline 4 & $\begin{array}{l}\text { Komatsu } \\
\text { et al. }\end{array}$ & 16824087 & 2006 & $\begin{array}{l}\text { Intra- } \\
\text { abdominal }\end{array}$ & Gastric cancer & Gastrectomy & After & $\begin{array}{l}\text { No recurrence/ } \\
9 \mathrm{~m}\end{array}$ \\
\hline 5 & Xu et al. & 21459731 & 2011 & $\begin{array}{l}\text { Intra- } \\
\text { abdominal }\end{array}$ & Cholangiocarcinoma & Pancreaticoduodenectomy & After & $\begin{array}{l}\text { No recurrence/ } \\
6 \mathrm{~m}\end{array}$ \\
\hline 7 & $\begin{array}{l}\text { Tomita } \\
\text { et al. }\end{array}$ & 24743485 & 2014 & Chest & $\begin{array}{l}\text { Lung } \\
\text { adenocarcinoma }\end{array}$ & Right upper lobectomy & After & $\begin{array}{l}\text { No recurrence/ } \\
60 \mathrm{~m}\end{array}$ \\
\hline 8 & $\begin{array}{l}\text { Shinohara } \\
\text { et al. }\end{array}$ & 27474466 & 2016 & Larynx & $\begin{array}{l}\text { Squamous cell } \\
\text { carcinoma }\end{array}$ & Laryngo-microsurgery & After & $\begin{array}{l}\text { No recurrence/ } \\
60 \mathrm{~m}\end{array}$ \\
\hline
\end{tabular}

$\mathrm{AF}$, aggressive fibromatosis.

postmenopausal status and short term endocrine therapy may be possible reasons.

AF usually occurs sporadically, and there are few reports of the association between AF with malignancies. Here, we conducted a review of the previously published cases of $\mathrm{AF}$ associated with malignancies in the English literature (Table 1). In most cases, AF occurred after a malignant tumor operation; AF occurred together with malignancies in only one case in the literature and in Case 2 in this report. Surgical trauma may be the main reason for $\mathrm{AF}$ in these cases. In fact, there have been few cases of AF reportedly mimicking lymph node metastasis after a malignant tumor operation according to the location or imaging examination, so it is necessary to conduct a preoperative FNAC biopsy for differential diagnosis. The cribriform-morular variant of papillary thyroid carcinoma (CMV-PTC), a very unusual subtype with better prognosis, is commonly seen in association with FAP (6). AF can also occur in association with the FAP gene mutation as a component of Gardner's syndrome (7), while in the present study, neither of the two patients had a family history of $F A P$ or pathologic features of CMV-PTC.

Recent studies demonstrated a relatively high frequency of $\beta$-catenin heterozygous mutations in $\mathrm{AF}$, and these mutations lead to posttranslational stabilization of the $\beta$-catenin protein, which plays a key role in the Wnt signaling pathway (8). Recent original studies indicate that $\mathrm{AF}$ is related to the 41 or 45 site mutation on exon 3 in the CTNNB1 gene on $3 \mathrm{p} 21$, resulting in $\beta$-catenin overexpression in nuclei by ICH detection (9). Therefore, $\beta$-catenin positivity in IHC is often used for the differential diagnosis of $\mathrm{AF}$. In these two cases, $\beta$-catenin positivity on IHC staining was consistent with the reported results.

In addition, papillary thyroid cancer with nodular fasciitis-like stroma is another subtype of papillary thyroid cancer according to the pathological features (10). It is a dual tumor comprising malignant epithelial proliferation and prominent mesenchymal proliferation resembling nodular fasciitis or fibromatosis, and IHC results have shown that the $\beta$-catenin staining is positive. One report proposed that PTC with nodular fasciitis-like stroma and $\beta$-catenin mutations should be renamed PTC with desmoidtype fibromatosis (11). Thus, there may be a relationship between AF and PTC with desmoid-type fibromatosis on the basis of the same pathological features and $\beta$-catenin mutation. With the acquisition of more data, further investigation may yield molecular determinants.

In summary, $\mathrm{AF}$ is a rare and benign but locally 
infiltrating and progressive tumor. AF can occur in association with malignancies, such as thyroid cancer. Whether a patient diagnosed with AF associated with thyroid cancer has a family history of FAP, FAP mutation, or $\beta$-catenin mutation should be given more attention. The treatment strategy in this situation includes surgical excision and combination with radiotherapy and endocrine therapy to reduce the recurrence rate.

\section{Acknowledgments}

Funding: This work was supported by the Science and Technology Innovation Plan of Southwest Hospital (SWH2016ZDCX4404, SWH2016JG022, SWH2016YSCXZD-10).

\section{Footnote}

Conflicts of Interest: All authors have completed the ICMJE uniform disclosure form (available at http://dx.doi. org/10.21037/tcr.2019.09.21). The authors have no conflicts of interest to declare.

Ethical Statement: The authors are accountable for all aspects of the work in ensuring that questions related to the accuracy or integrity of any part of the work are appropriately investigated and resolved. All procedures performed in studies involving human participants were in accordance with the ethical standards of the institutional and/or national research committee(s) and with the Helsinki Declaration (as revised in 2013). Written informed consent was obtained from the patient for publication of this manuscript and any accompanying images.

Open Access Statement: This is an Open Access article distributed in accordance with the Creative Commons Attribution-NonCommercial-NoDerivs 4.0 International License (CC BY-NC-ND 4.0), which permits the noncommercial replication and distribution of the article with the strict proviso that no changes or edits are made and the original work is properly cited (including links to both the formal publication through the relevant DOI and the license).
See: https://creativecommons.org/licenses/by-nc-nd/4.0/.

\section{References}

1. Joglekar SB, Rose PS, Sim F, et al. Current perspectives on desmoid tumors: the mayo clinic approach. Cancers (Basel) 2011;3:3143-55.

2. Molloy AP, Hutchinson B, O'Toole GC. Extra-abdominal desmoid tumours: a review of the literature. Sarcoma 2012;2012:578052.

3. Kransdorf MJ. Malignant soft-tissue tumors in a large referral population: distribution of diagnoses by age, sex, and location. AJR Am J Roentgenol 1995;164:129-34.

4. Eastley N, McCulloch T, Esler C, et al. Extra-abdominal desmoid fibromatosis: A review of management, current guidance and unanswered questions. Eur J Surg Oncol 2016;42:1071-83.

5. Fiore M, MacNeill A, Gronchi A, et al. Desmoid-Type Fibromatosis: Evolving Treatment Standards. Surg Oncol Clin N Am 2016;25:803-26.

6. Pradhan D, Sharma A, Mohanty SK. Cribriform-morular variant of papillary thyroid carcinoma. Pathol Res Pract 2015;211:712-6.

7. Misemer BS, Skubitz AP, Carlos Manivel J, et al. Expression of FAP, ADAM12, WISP1, and SOX11 is heterogeneous in aggressive fibromatosis and spatially relates to the histologic features of tumor activity. Cancer Med 2014;3:81-90.

8. Fisher C, Thway K. Aggressive fibromatosis. Pathology 2014;46:135-40.

9. van Broekhoven DL, Verhoef C, Grünhagen DJ, et al. Prognostic value of CTNNB1 gene mutation in primary sporadic aggressive fibromatosis. Ann Surg Oncol 2015;22:1464-70.

10. Na KY, Kim HS, Sung JY, et al. Papillary Carcinoma of the Thyroid Gland with Nodular Fasciitis-like Stroma. Korean J Pathol 2013;47:167-71.

11. Rebecchini C, Nobile A, Piana S, et al. Papillary thyroid carcinoma with nodular fasciitis-like stroma and $\beta$-catenin mutations should be renamed papillary thyroid carcinoma with desmoid-type fibromatosis. Mod Pathol 2017;30:236-45.
Cite this article as: Li Y, Li S, Qi X, Fu W, Zhang F, Yang $\mathrm{X}$. Aggressive fibromatosis-associated with papillary thyroid cancer: two cases and a brief review. Transl Cancer Res 2019;8(5):2211-2215. doi: 10.21037/tcr.2019.09.21 